\title{
Pesquisas temáticas no Laboratório de Arqueologia Romana Provincial (LARP/MAE/USP)
}

\author{
Maria Isabel D'Agostino Fleming
} mi.fleming@usp.br

Resumo: Esta comunicação apresenta as pesquisas temáticas do Laboratório de Arqueologia Romana Provincial do Museu de Arqueologia e Etnologia da Universidade de São Paulo (LARP), tendo em vista suas atividades em duas frentes, a acadêmica e a de cunho educativo, esta última veiculada por seus Projetos Piloto, através de web site próprio, voltados para a comunidade de educadores e alunos de todas as faixas etárias e formações escolares.As pesquisas individuais dos membros do LARP, voltadas para uma ampla gama de questões relacionadas à atuação de Roma em suas províncias são o ponto de referência para a organização dos recortes temáticos que expressam a interlocuçãodo grupo, um dos objetivos do Laboratório.

Palavras-chave: Províncias romanas; Pesquisas temáticas; Web SIG; Aplicativos web; Realidade Aumentada.

\begin{abstract}
This communication presents the thematical researches of the Laboratory of Provincial Roman Archaeology of the Museum of Archaeology and Ethnology of the University of São Paulo (LPRA), focusing in two fronts, the academic one and that of educative matters, this latter vehiculated by the Laboratory's Pilot Projects, by means of its own web site, devoted to the community of educators and students of all ages ranges and scholarly formations. The individual researches of the members of LPRA, regarding an ample spectrum of questions related to the presence of Rome in its provinces are the reference point to the organization of the thematic focuses which express the interlocution of the group, one of the goals of the Laboratory.
\end{abstract}

Keywords: Roman Provinces; Thematical researches; Web SIG; Web applications; Augmented reality.

\section{O que é o LARP}

O Laboratório de Arqueologia Romana Provincial-LARP é um dos laboratórios temáticos do Museu de Arqueologia e Etnologia da Universidade de São Paulo e nasceu em 2011, com auxílio da FAPESP, a partir de uma experiência de pesquisa de um Grupo de Trabalho do CNPq "Formas de contato e processos de transformação no Mediterrâneo Antigo: Roma e suas províncias", liderado pela Profa. Dra. Maria Isabel D’Agostino Fleming. O GT-CNPq acumulou um elenco de questões sobre a atuação romana nas províncias que levaram à proposta de ampliação e diversificação do espaço científico-acadêmico que ocupava, de forma 
a ter os necessários níveis de expressão compatíveis com um museu universitário, na área de pesquisa, docência e extensão universitária.Ou seja, o LARP deveria se adequar ao status de unidade que foi alcançado pelos Museus da Universidade de São Paulo, quando em 2010 deixou de ser Órgão de Integração após um processo de mais de 25 anos, tendo em vista sua atuação no ensino de pós-graduação desde a década de 1970 e de disciplinas optativas de graduaçãooficializadas na década de 1990.Nesse sentido, em primeiro lugar, visou-se o aprofundamento das pesquisas na área de arqueologia romana, centro de referência das demais atividades, e, ao mesmo tempo, a criação de canais de contato com pesquisadores e alunos, com a aplicação de meios específicos, de forma a divulgar, através de website próprio, o material produzido pelo Laboratório. Incluem-se neste item os resultados das pesquisas em forma de textos; pesquisas na área de Sistema de Informação Geográfica, como banco de imagens referentes a sítios e vestígios arqueológicos das regiões geográficas analisadas; e projetos diretamente voltados para a esfera educativa, com recursos da internet.Trata-se, então, de duas frentes de pesquisa: a acadêmica e a de cunho educativo,realizadaatravés dos Projetos Piloto. Ambas as frentes são frutos dessa mesma articulação de pesquisas dos membros do LARP.

Os temas gerais de investigação aos quais estão associados os projetos do LARP são imperialismo romano; exército; romanização; alteridade/identidade; identidade e discurso; religião e política; urbanismo/urbanização; transformação dos espaços públicos; iconografia; espaço doméstico; tecnologia, produção e consumo; território e paisagem, entre outros. Por sua vez, as províncias romanas pesquisadas são Britânia, Hispânia e Lusitânia, Gális, Egito, Norte da África, Palestina, com um contraponto da Itália, sua área central.

Antes de passarmos às pesquisas temáticas acadêmicas, o centro de minha apresentação nesta mesa redonda, farei uma breve introdução dos Projetos Piloto.

\section{Projetos Piloto}

São projetos apoiados por um Banco de Dados (textos e imagens para uso dos projetos com recursos da internet): Web Sig; Roma 360; Domus Romana; Domus Romana com Realidade Aumentada:

\section{Web SIG}

Trata-se de um geovisualizador com as seguintes propriedades: 
- permite observar a espacialidade da presença romana na Península lbérica e Palestina e o processo de territorialização da mesma;

- contempla os dados coletados em prospecções ocorridas de 2012 a 2014: 157 referências de localidades no banco de imagens;

Seus objetivos são:

2012 - georreferenciar alguns sítios castrejos e romanos em Portugal (Fig. 1);

2013 - prospectar e georrefenciar alguns sítios romanos no Noroeste da Península Ibérica

- Bracara Augusta, Lucus, Asturica e a região das Las Medulas;

2014 - georreferenciar alguns sítios romanos na Palestina (Fig. 2).

\section{Inserir Figuras 1 e 2}

\section{Roma 360}

A proposta deste aplicativo web, de autoria de Alex da Silva Martire, é apresentar o mapa da capital do Império no séc. IV d.C. (SHEPHERD, 1923). O período escolhido deve-se à razão de que a maior parte dos monumentos da paisagem de Roma é do período tardio imperial, o que traz facilidade de consulta às referências fotográficas e imagéticas disponíveis atualmente. Optou-se por uma versão estilizada dos edifícios para não tornar o processo demorado e, principalmente, pesado demais para a visualização nos computadores.

\section{Inserir Figura 3}

\section{Domus Romana}

O projeto apresenta a reconstituição de uma casa romana pompeiana e suas funcionalidades. Seu caráter didático tem como objetivo alcançar educadores e alunos de todas as faixas etárias e formações escolares. A parte digital, de criação e modelagem no Autodesk Maya 2014 e sua renderização são de responsabilidade de Alex Martire. O projeto conta ainda com uma galeria de imagens e objetos e as contribuições do grupo para a pesquisa consistem em explicações sobre a construção da domus pompeiana, além da redação de textos de apoio para a completa assimilação do conteúdo do projeto, que se destaca por ser um aplicativo multimídia criado apenas por arqueólogos especializados em Roma antiga. É um trabalho ímpar no meio acadêmico dentro de sua proposta (Fig. 4).

Inserir Figura 4

(C) Rev. Arqueologia Pública Campinas, SP v.9 No.(11) \begin{tabular}{|l|l} 
p.105-113 & suplemento
\end{tabular} ISSN 2237-8294 


\section{Domus Romana com Realidade Aumentada}

Trata-se de uma planta arquitetônica interativa, de autoria de Alex Martire, para a qual foi utilizada uma plataforma mobile Android para a geração de Realidade Aumentada. Para sua utilização basta usar o aplicativo instalado no smartphone ou tablet e apontar o dispositivo para a planta da domus impressa em papel para visualizar os cômodos em forma de pop-up, com os personagens que se movimentam dentro da casa.

Este projeto permite transformar a experiência individual da participação no projeto da Domus Romana pela experiência coletiva dos alunos, uma vez que vários poderão, ao mesmo tempo, ter acesso à domus digital (Fig. 5).

\section{Inserir Figura 5}

\section{As pesquisas temáticas}

A base mesma de atuação do LARP é a pesquisa desenvolvida pelos seus membros, docentes da USP, UFPE e UFRN, de pós-doutorandos, doutorandos, mestrandos e de alunos de iniciação científica do MAE-USP. A partir desse núcleo de pesquisas foram organizados os recortes temáticos que, assim como os Projetos Piloto apresentados acima, evidenciam um trabalho de interlocução do grupo,um dos objetivos do LARP. O resultado deverá ser a publicação de um livro editado pela Editora Annablume e co-editado pela FAPESP, processo que aguarda parecer.

Assim, as pesquisas estão articuladas por três temas: Urbanização e Ambiente Construído; Religião e Práticas Mortuárias; Economia e Tecnologia, que discutem questões relacionadas às províncias da Hispânia, Palestina, Gália, Egito, Britânia, algumas confrontadas com a área central na Itália.

\section{Tema: Urbanização e ambiente construído}

A pesquisa Urbanização e Território nas províncias da Hispânia Romana: discutindo conceitosestá associada aos projetos "Estudo comparativo do impacto da presença romana no Oriente (Siro-Palestina) e Ocidente (Península lbérica) a partir das moedas emitidas entre os séculos I e III d.C"., de Vagner Carvalheiro Porto; "A Lusitania e a Iberia. Um estudo da mudança na urbanização pré e pós-Romanização (da pré-conquista romana ao Baixo Império séc. II a.C. ao V d.C.)", de Irmina Doneux Santos; "Transformações culturais e modelos espaciais no estudo da paisagem da romanização no noroeste peninsular: a integração do 
mundo romano durante o Alto Império", de Elaine Cristina Carvalho da Silva; "As Thermae e Balneae nas Hispaniae Romanae - II a.C.- III d.C.", de Alex dos Santos Almeida.

A pesquisa analisa como, através do registro material, pode-se chegar a um quadro mais efetivo dos possíveis padrões de ocupação romana nos territórios conquistados. Discute os conceitos de território e urbanização em duas vertentes principais: flexibilização e padronização. Esta temática envolve as transformações na urbanização pré e pósromanização na Península Ibérica refletidas nas formas espaciais e arquitetônicas em suas múltiplas funções políticas, econômicas, sociais, culturais, religiosas, de lazer e entretenimento. Por sua vez, a investigação do urbanismo pelo viés numismático revela as diferentes estratégias políticas de diálogo entre Roma e províncias através da emissão, circulação e iconografia monetária.

\section{Tema: Religião e Práticas Mortuárias}

A pesquisa Religião e Práticas Mortuárias no Império Romanoestá associada aos projetos "Violência e práticas mortuárias na Britannia", de Renato Pinto; "Romanização, crenças funerárias e identidade cultural no Egito Romano", de Marcia Severina Vasques; "O ritual da morte e os povos castrejos do noroeste de Portugal', de Silvana Trombetta; "Os panteões galo-romanos nos pilares e "colunas de Júpiter", de Tatiana Bina; "Comunicação Visual na Antiguidade Cristã: a construção de um discurso imagético cristão do Ante Pacem ao Tempora Christiana (s. III-V d.C.), de Alessandro Mortaio Gregori.

A pesquisa discute duas das atuais grandes tendências historiográficas nesse campo: a importância das práticas e ritos como norteadores da "religião romana", que não existiria como conjunto de dogmas, mas como conjunto de ações constituidoras da romanidade, e os questionamentos e contribuições das teorias pós-coloniais dentro dos debates de interação cultural. Dentro desta abordagem, procura-se acessar, através do registro material, a trajetória religiosa e as práticas mortuárias por meio da "performance", ou seja do rito, um aspecto muito importante na construção da religiosidade e identidade romanas e, por consequência, presente nas políticas de "romanização".

\section{Tema: Economia e Tecnologia}


A pesquisa Cerâmicas finas e comuns: sua produção no contexto provincial romano está associada aos projetos "A cerâmica do noroeste da Península lbérica: permanências e transformações na produção cerâmica de tradição local', de Maria Isabel D'Agostino Fleming, e "Análise e distribuição espacial de lamparinas romanas discus: o caso das províncias da Palestina e do norte da África", de Marcio Teixeira Bastos.

A pesquisa na alisa as semelhanças e as diferenças de dois tipos específicos de produção cerâmica em distintas regiões do Império: as cerâmicas comuns domésticas do noroeste da Península Ibérica e as cerâmicas de iluminação produzidas por oficinas especializadas na Palestina e Norte da África. O tema da economia e da tecnologia insere-se nas discussões sobre as relações sociais que permeiam as duas produções cerâmicas e sua integração nas redes comerciais e culturais no âmbito imperial romano. O esforço de identificação dos grupos sociais envolvidos é um dos objetivos específicos da discussão da pesquisa, ou seja, a identificação de todos aqueles pertencentes a um determinado grupo social, partes do mesmo conjunto de significados e ligados a um artefato específico. Nos casos discutidos, esses grupos seriam o universo masculino e feminino na Península lbérica e, na Palestina romana, os grupos monoteístas (samaritanos, cristãos, judeus) e os adeptos da religião tradicional romana.

\section{Referências bibliográficas}

SHEPHERD, W.R. Historical Atlas. New York: Henry Holt and Company, 1923.

Figuras e legendas

\begin{tabular}{|l|l|l|l|l|l|l}
\hline ( Rev. Arqueologia Pública & Campinas, SP & v.9 & No.(11) & p.105-113 & suplemento & ISSN 2237-8294 \\
\hline
\end{tabular}


느 II SEMANA DE

ORQUEOLOGIA

N DA UNICAMP

ATAS

HISTÓRIA E CULTURA MATERIAL: DESAFIOS DA CONTEMPORANEIDAD

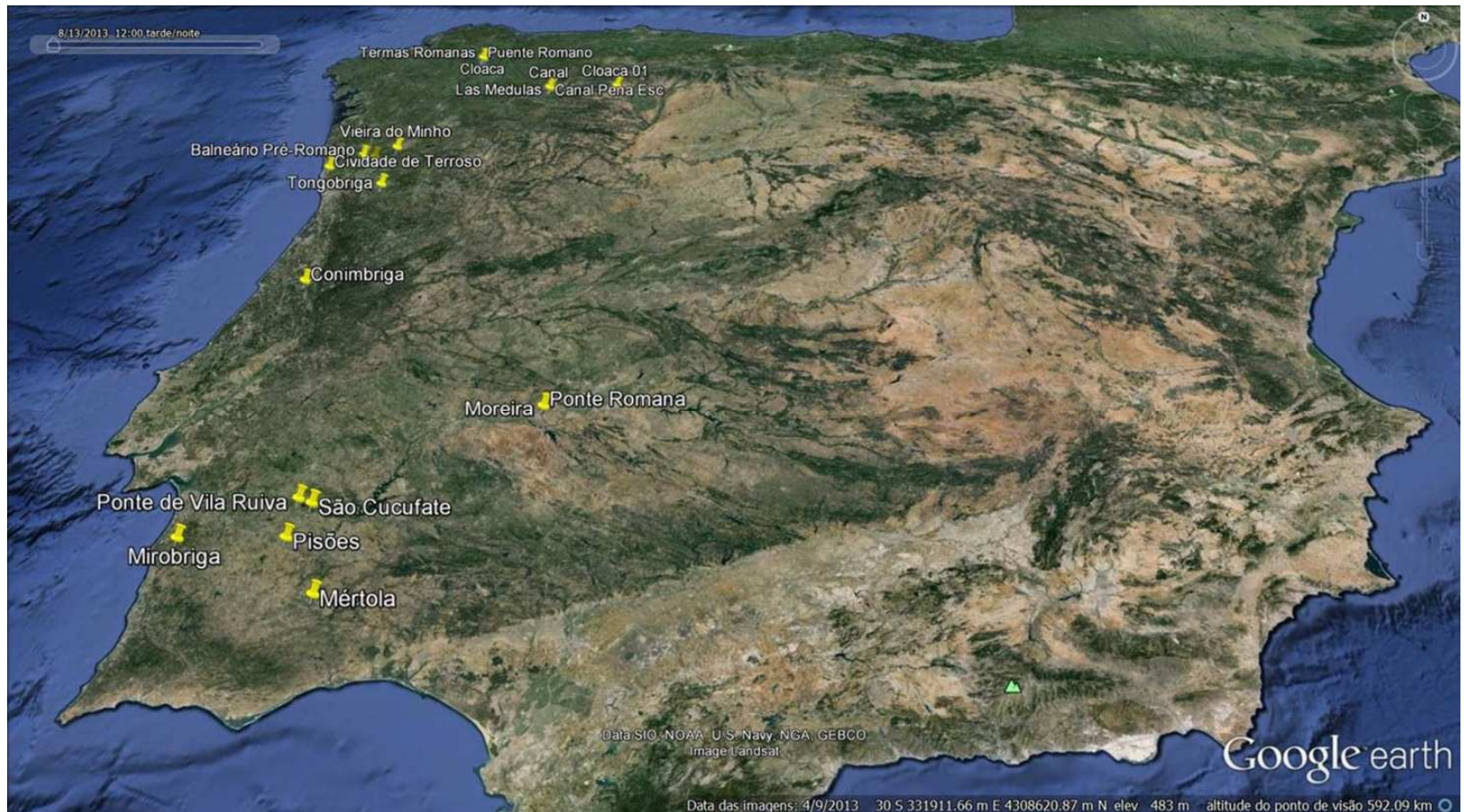

Figura 1 -Georreferencimento de sítios castrejos e romanos em Portugal.

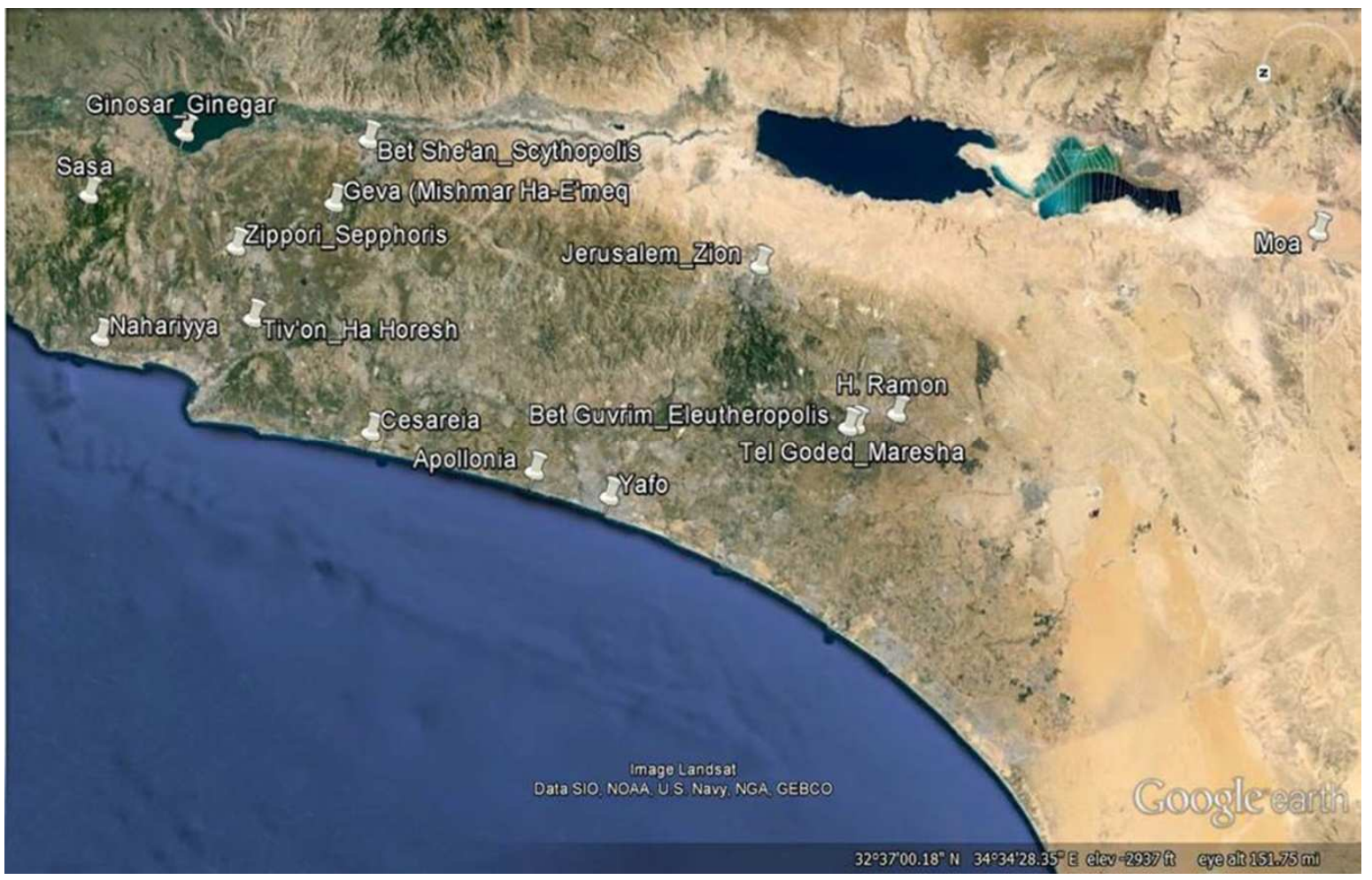

Figura 2-Georreferencimento de sítios castrejos e romanos na Palestina.

\begin{tabular}{|l|l|l|l|l|l|l|}
\hline (C) Rev. Arqueologia Pública & Campinas, SP & v.9 & No.(11) & p.105-113 & suplemento & ISSN 2237-8294
\end{tabular}


느 II SEMANA DE

O ARQUEOLOGIA

N DA UNICAMP

HISTÓRIA E CULTURA MATERIAL: DESAFIOS DA CONTEMPORANEIDADE

ATAS

Laboratório de Arqueologia Romana Provincial | ROMA360

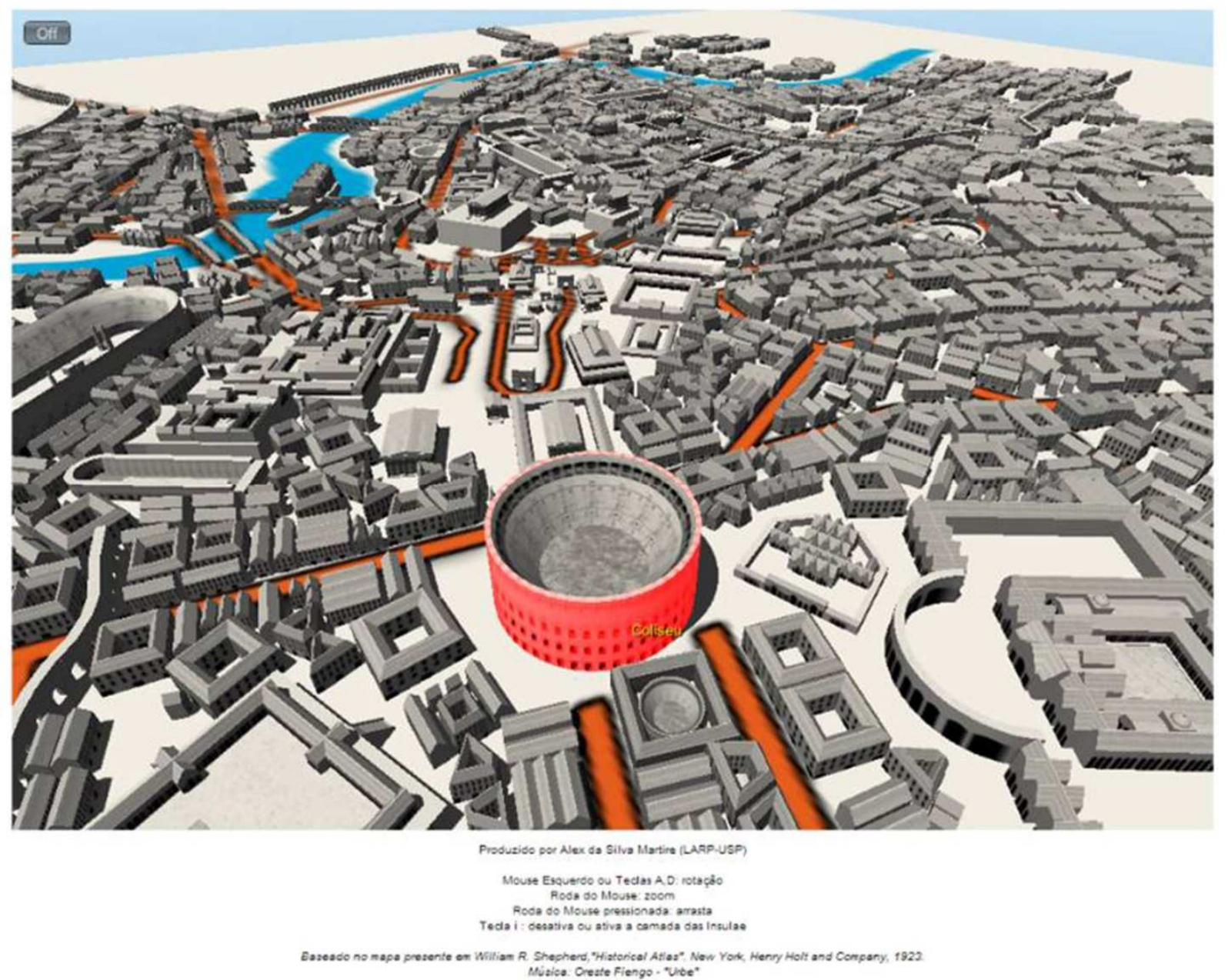

Figura 3-Roma 360 rodando diretamente no navegador de internet.

$\overbrace{\substack{\pi \\ \pi \\ \pi}}^{N}$

(C Rev. Arqueologia Pública

Campinas, SP

\begin{tabular}{l|l} 
v.9 & No.(11)
\end{tabular}

p.105-113

suplemento

ISSN 2237-8294 


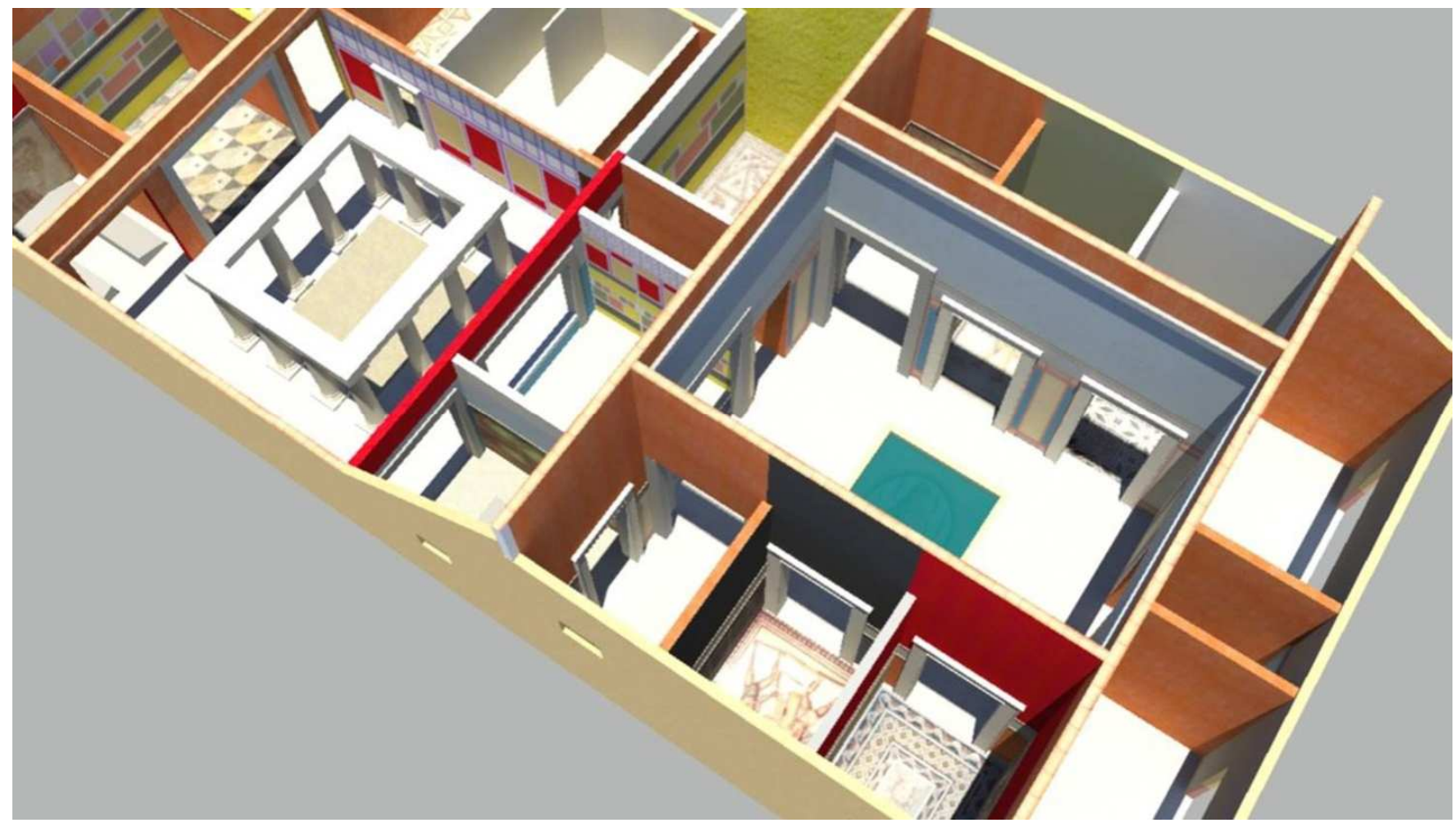

Figura 4-Renderização da Domus no Autodesk Maya 2014: perspectiva superior.

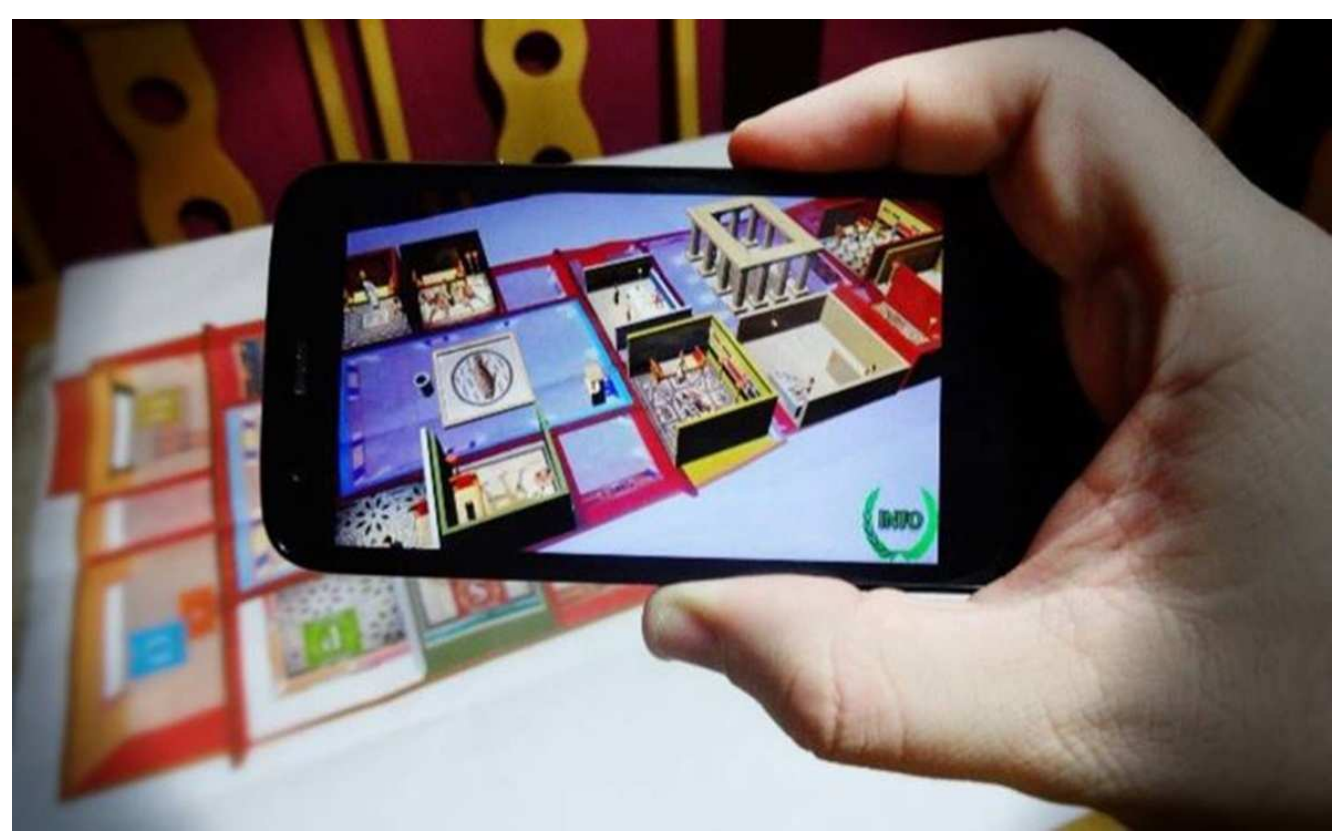

Figura 5-Domus Romana com Realidade Aumentada, com o uso de um smartphone.

\begin{tabular}{|l|l|l|l|l|l|l}
\hline (C Rev. Arqueologia Pública & Campinas, SP & v.9 & No.(11) & p.105-113 & suplemento & ISSN 2237-8294 \\
\hline
\end{tabular}

